\title{
$\mathrm{R}$ e g is t ro
}

\section{Relatorio referente ao ano de 1934, apresentado pelo Prof. Waldemar Martins Ferreira, Diretor em exer- cicio da Faculdade de Direito de São Paulo}

\section{S u mário}

1. A criação da Universidade de São Paulo pelo decr. n. 6.283, de 25 de janeiro de 1934, e a transferencia ao Estado de São Paulo da Faculdade de Direito, pelo decr. n. 24.102, de 10 de abril de 1934.

2. A manifestação da Congregação dos Professores a favor da transferencia.

3. A incorporação da Faculdade de Direito á Universidade de São Paulo pelo decr. n. 6.429, de 9 de maio de 1934, que lhe deu novo regulamento.

4. A instalação dos serviços reitoriais da Universidade de São Paulo no edificio da Faculdade de Direito.

5. A criação do Colegio Universitario pelo decr. n. 6.283, de 25 de janeiro de 1934, e o seu novo regulamento pelo decr. n. 6.829, de 30 de novembro de 1934.

6. A aprovação dos Estatutos da Universidade de S. Paulo pelo governo federal o os termos do decr. n. 39 , de 3 de setembro de 1934.

7. A adaptação da Faculdade de Direito ao seu novio regulamento estadual.

8. As matriculas aos cursos normais da Faculdade de Direito no ano letivo de 1934 . 
9. A obrigatoriedade da frequencia ás aulas dos cursos normais da Faculdade de Direito.

10. A construção do novo edificio da Faculdade de Direito e a sua instalação no novo pavilhão da rua do Riachuelo.

11. Os orçamentos da receita e da despeza da Faculdade de Direito para o ano letivo de 1935.

12. Observações a proposito do Curso de Doutorado.

13. Elogio aos funcionarios da Faculdade de Direito.

14. Nota final.

\author{
ANEXO N. 1. \\ Relatorio do Secretario dos serviços da Secretaria no \\ ano letivo de 1934. \\ ANEXO N. 2. \\ Relatorio dos serviços, movimento e mudança de Biblio- \\ teca durante o ano de 1934. \\ ANEXO N. 3. \\ Relatorio dos serviços da Tesouraria durante 0 ano \\ letivo de 1934.
}

\title{
Relatorio
}

1. Criada, pelo decr. n. 6.283, de 25 de janearo de 1934, a Universidade de São Paulo, devia entrar na sua composição uma Faculdade de Direito. Podia o governo do Estado erigir novo estabelecimento de ensino juridico. Sobrarvam-lhe recursos para isso. Preferiu, no entanto, fosse o instituto universitario com tal finalidade a Fa. culdade de Direito de São Paulo, o mais que centenario curso juridi. co, fundado pela lei de 11 de agosto de 1827 e que tantos e assinalados serviços prestou e vem prestando à cultura brasileira.

Animado desse proposito, entrou o governo do Estado em entendimento com o então chefe do Governo Prvisorio. Dele resultou formula felicissima, permitindo a incorporação da Faculdade de Di. reito á Universidade oficial federal. Transferiu a União, por força do decr. n. 24.102, de 10 de abril de 1934, ao Estado de São Paulo a Faculdade de Direito, com o seu predio, as suas instajações e tudo o mais que lhe formava o patrimonio, para aquele efeito. 
Subordinou aquela transferencia, todavia, a algumas condições. Continuaria a Faculdade de Direito a ter o caráter e a gozar das mesmas prerrogativas dos institutos of iciais congeneres da União. Garantiu aos seus professores e funcionarios os direitos e as vantagens assegurados pelas leis federais, inclusivé o pagamento dos respectivos vencimentos pelo Tesouro Federal, sem embargo de outros direitos que as leis estaduaes outorguem a professores e funccionarios de igual categoria.

Os professores e funccionarios nomeados depois da publicação daquele decreto terão os seus direitos e deveres regulados pelas leis estaduais. A organização didática, o regime escolar, a nomeação do diretor e do pessoal docente e administrativo passariam a obedecer às disposições dos Estatutos da Universidade, desde que aprovados pelo governo federal, ao qual reverterá, e isso ficou expresso em caso de extinção desta, bem assim no de o exigirem os interesses do ensino, a Faculdade de Direito, com o seu patrimonio.

Operou.se, portanto, notavel transformação na vida da Faculdade de Direito de São Paulo, tornada estabelecimento de ensino universitario estadual, sem perda do seu caráter oficial federal.

2. Tomando conhecimento daquele decreto, em Congregação de 30 de abril de 1934, os professores da Faculdade de Direito aprovaram - lançandose em ata de sues trabalhos e dando-se-lhe larga publicidade - expressiva moção. Manifestaram, por via dela, o seu regosijo por aquele ato e, nottadamente, pela instalação da Universidade de São Paulo, realização de velho sonho paulista. E formularam os melhores votos por que o grande instituto universitario, fadado a ser o renovador dos estudos e labores culturais do pais, contasse sempre com a adesão e o esforço de quantos aspiram o engrandecimento deste glorioso recanto da terra brasileira.

Nomeou-se uma comissão de profiessores, incumbida de rever o regulamento da Faculdade de Direito e o respetivo projeto, pela Congregação aprovado, foi enviado ao governo do Estado.

3. Este, pelo decr. n. 6.429, de 9 de maio de 1934, incorporando a Faculdade de Direito, nos termos do decreto felderal n. 24.102, de 10 de abril de 1934, á Universidade de São Paulo, submeteu-a ao regulamento, que com ele baixou, sem prejuizo das modificações de futuro introduzidas pelos Estatutos desta.

Calcadio, como não podia deixar de ser, nas leis e regulamentos federais em vigor, exarou aquele algumas modificações, no atinente às disciplinas do curso de bacharelado. Ajuntou-lhe mais uma cadeira de Direito Comercial. Outra de Direito Civil. Mais outra de Direito Judiciario Civil. Restaurou a de Direito Romano. Transferiu para ele a de Direito Privado Internacional. E ficaram os cinco anos. com estas materias: 
a) primeiro ano:

Primeira cadeira - Introdução á Clencia do Direito; segunda - Economia Politica e Ciencia idas Finanças; terceira - Direito Romano; e quarta - Direito Civil (Parte geral e teoria geral das obri. gações).

b) segundo ano:

Primeira cadeira - Direito Civil (Obrigações em especie e contratos); segunda - Direito Penal (Parte geral); terceira - Direito Publico Constitucional; quarta - Direito Comercial (Parte geral. Atos de comercio. 0 comerciante. As sociedades).

c) terceiro ano:

Primeira cadeira - Direito Civil (Direito das cousas); segunda - Direito Penal (Dos crimes em especie è regime penitenciario); terceira - Direito Comercial ( 0 estabelecimento comercial. Contratos e obrigações. Titulos de credito); e quarta - Direito Judiciario Civil.

d) quarto ano:

Primeira cadeira - Direito Civil (Familia e sucessões); segunda - Direito Comercial (Maritimo e falencias); terceira - Direito Judiciario Civil; e quarta - Medicina Legal.

(e) quinto ano:

Primeira cadeira - Direito Judiciario Civil; segunda - Direito Judiciario Penal; terceira -- Direito Privado Internacional; e quarta - Direito Administrativo e Ciencia da Administração.

Reuniu o decr. n. 6.429, de 9 de maio de 1934, as tres secções, em que o decr. n. 19.852, de 11 de abril de 1931, havia seriado o curso de doutorado, numa unica, dividida em dois anos, com as seguintes materias:

a) primeiro ano:

Primeira cadeira - Direito Publico (Teoria geral do Estado e partes espleciais); segunda - Historia do Direito Nacional; terceira - Direito Civil Comparado; e quarta - Criminologia.

b) segundo ano:

Primeira cadeira - Economia e Legislação Social; segunda Direito Publico Internacional; terceira - Ciencia das Finanças; e, quarta - Filosofia do Direito.

4. Integrada na Universidade de São Paulo, começou a Faculdade de Direito por dar-lhe guarida. Instalaram-se no seu edificio os serviços reitoriais: a Reitoria, a Secretaria, a Contadoria. Numa de suas salas sempre se reuniu o Conselho Universitario, de cujos trabalhos tem coparticipado por via de seus dois representantes: o diretor em exercicio e o proflessor eleito pela Congregação. 
Tanto que, no novo predio em construção, se tornou possivel a ocupação de algumas de suas dependencias, numa das salas do seu terceiro andar se localizou a Secretaria da Universidade de São Paulo, que ali funciona, ha muitos mêses, regularmente.

Resolveu, mesmo o Conselho. Universitario, numa de suas sessões ultimas, aprovar o projeto de, no predio em construção para a Faculdade de Direito, construir.se mais um andar, reservado para a Universidade de São Paulo. A planta, nesse sentido elaborada, tambem aprovada foi e está em vias de execução.

5. No mesmo dia, em que lançou a Universildalde de São Paulo, instituiu o governo do Estado, ao lado dela, pelo decr. n. 6.283, de 25 de janeiro de 1934, o Colegio Universitario, com o objetivo de completar a educação secundaria dos candidatos aos institutos universitarios e orienta-los na direção das escolas a que se destinarem. Veiu ele a substituir, por uma de suas secções - a primeira, o Curso Pre-Juridico. Entrou a funcionar na Faculdade de Direito, em duas séries, pelas quais se distribuiram as materias, deste modo:

a) primeira série:

Latim. Historia da Literatura. Biologia Geral. Psicologia. Historia da Civilisação. Economia e Estatistica.

b) segundar série:

Latim. Historia da Litteratura. Logica. Historia da Filosofia. Geografia e Cosmografia. Higiene. Sociologia.

Modificando e ampliando os dispositivos regulamentares do Colegio Universitario, nos termos de proposta do Conselho Universitario, o decr. n. 6.829, de 30 de novembro de 1934, deu-lhe dois orgãos administrativos:

a) o diretor - o do instituto universitario a que a secção estiver anexa, com a incumbencia de superintender-lhe o ensino e a administração;

b) o conselho tecnico, compostos de todos os profiessores em exercicio, com funções consultivas sobre assuntos disciplinares e didaticos.

6. Aprovou o governo federal, pelo decr. n. 39, de 3 de setem. bro de 1934, atendendo a proposta do Conselho Nacional de Educação, os Estatutos da Universidade de São Paulo, nos quais se estabeleceu a mesma seriação das disciplinas dos dois cursos normais da Faculdade de Direito: o de bacharelado e o de doutorado, que já havia feito o decr. n. 6.429, de 9 de maio de 1934.

Aplicar-se-á ela, como resolveu a Congregação, no primeiro ano do curso de 1935. 
7. Causam sempre as refórmas do ensino, durante o ano leti. vo, serios embaraços, em detrimento do proprio ensino. A adaptação, a que se procedeu, para o efeito da incorporação da Faculdade de Direito á Universidade de São Paulo, trouxe dificuldades á inauguração e funcionamento do curso de doutorado e do Colegio Universitario, praticamente reduzidos a um semestre.

Desapareceriam todos os males disso decorrentes, se outros não houvesse implantado a lei $\mathrm{n}$. , de de dezembro de 1934. Determinaram, com efeito, os Estatutos da Universidade de São Paulo, ant. 121, o inicio do ano letivo dos institutos universitarios em 1 de março e o seu encerramento em 14 de novembro de cada ano, com férias de 21 de junho a 15 de julho. Aquela lei, entretanto, estatuiu, no art. 3, que "o aluno de qualquer curso, que não obtiver nota de promoção ou de aprovação em uma ou duas disciplinas, poderá submeter-se a exame na primeira quinzena de março". Ora, pelo regulamento da Faculdade de Direito, e para que pudesse o ano letivo iniciar-se em 1 de março, haveria uma segunda epoca de provas, na primeira quinzena de fevereiro, não somente para os que não tivessem podido inscrever-se na primeira, senão tambem para os que, nela, tivessem sido aprovaldos em todas as cadeiras do ano, menos uma.

Se aquela lei tivesse permitido o exame aos a que procurou favorecer, em segunda epoca, e não, como o fez, declaradamente, na primeira quinzena de março, não daria o resultado de diminuir o ano letivo, com espaçar-lhe o inicio regular, em prejuizo do ensino.

8. Atingiram as matriculas nos cursos normais da Faculdade de Direito, no ano letivo de 1934, a numero anteriormente jamais alcançado. Não obstante não haver funcionado o quinto ano, por terem se bacharelado antes, por concessão legal, os que deveriam cursa-lo, foram elas:

a) no curso de bacharelado:

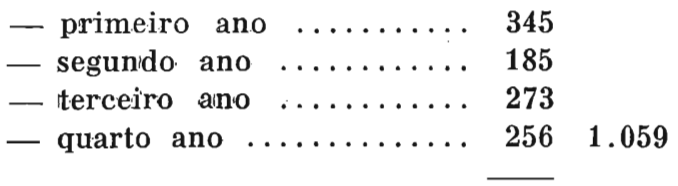

b) no curso de doutorado:

$$
\begin{array}{ccccc}
\text { Z primeiro ano } \ldots \ldots \ldots \ldots & 26 & \\
\text { - segundo ano } \ldots \ldots \ldots \ldots & 15 & 41 \\
\text { Total } \ldots \ldots \ldots \ldots \ldots \ldots & & 1.100
\end{array}
$$


Para a eficiencia, aindia assim relativa, do ensino, foram as aulas desdobradas e cada ano dividido em duas turmas.

9. Se tal foi o numero total dias matriculas, declinou muito o da frequencia ás aulas, por varios motivios, que não serão agora passados em revista. Cierto é, entretanto, que alguns professores entendiam não lhes ciaber a missão fiscalizadora da frequencia, de um lado; e, de outro, contavam os estudantes com a munificencia de uma dispensa ministerial, á vespera dos exames, como sempre tem acontecido. Esses e outros motivos contribuiram para que a frequenıcia ás aulas fosse muito irregular.

Procurou o regulamento da Faculdade de Direito obviar os males disso resultantes, com lançiar, no art. 118, o principio de não poder prestar exame final na primeira epoca (dezembro) o aluno que não tiver comparecido a dois terços, no minimo, das aulas dadas em cada cadeira, cujo exame pretenda fazer.

Como a verificação da presença pelo tradicional sistema da chamada pelo bedel, além de outros defeitos facilm'ente compreensiveìs, consumia não poucas vêses mais de quinze minutos, reduzindo quasi á metade os quarenta e cinco minutos de duração da aula, o regulamento instituiu o sistema da assinatura no livro de presença ou de comparecimentos, devidamente autenticado. Pelo disposto no art. 104 e seus paragrafos, iniciada a aula o bedel irá apresentando aos estudantes o livro de presença, no qual cada um assinará, indicando o numero de sua matricula. Finda a aula, o professor encerrará o ponto.

Deu esse sistema o melhor resultado, pois somente pode ser fraudado pela assinatura de um por outro, facilmente verificavel e punivel.

Consignou, ademais, o art. 123, que, para apurar a frequencia necessaria ao exame de primeira epoca, organizará a secretaria, até ao dia cinco de cada mês, o quadro de comparecimento e faltas dos alunos, o qual, visado pelo diretor, será afixado para ciencia dos interessados. Dentro de dez dias, contados da afixação do quadro, poderão os alunos reclamar contra erros nele contidos, resolvendo o professor, de plano, em decisão da qual não cabe recurso. De quinze a vinte de novembro será feita a apuração final da frequencia, inclusivé as relativas á primeira quinzena daquele mês. A apuração é feita pelos escriturarios, sob direção, vigilancia e responsabilidade do secretario.

Nessas condições, não puderam fazer exames, em primeira epoca, por falta de frequencia: 

a) no primeiro ano:
primeira cadeira . . . . . . . . . 47 alunos
segunda cadeira . . . . . . . . 78 alunos
b) no segundo ano:
primeira cadeira . . . . . . . . 46 alunos
segunda cadeira. . . . . . . . 56 alunos
terceira cadeira . . . . . . . . 54 alunos
c) no terceiro ano:
primeira cadeira . . . . . . . . 64 alunos
segunda cadeira . . . . . . . . . 79 alunos
terceira cadeira . . . . . . . . 88 alunos
d) no quarto ano:
primeira cadeira . . . . . . . . 94 alunos
segunda cadeira .. . . . . . . . . 125 alunos
terceira cadeira .. . . . . . . . . 101 alunos
quarta cadeira .......... . 99 alunos.

Deu isso ensanchas a que os prejudicados pelas suas proprias gazetas se dirigissem ao governo do Estado, solicitando dispensa da frequencia afim de poderem ser admitidos a exames na primeira epocla.

Pedildas, pelo sr. secretario da Educação, informações a respeito, deu-lhes o vice-diretor da Faculdade de Direito, que era o sinatario deste, no exercicio do cargo de diretor.

Foram as seguintes:

"Como muito bem o demonstrou o Exmo. Sr. Reitor da Universidade de São Paulo, não é de deferirase o pedido formulado por varios alunos da Faculdade de Direito no sentido de serem todos, indistintamente, admitidos á inscrição para as provas finais deste ano letivo em primeira epoca, não obstante não terem a frequencia minima de dois terços das aulas dadas de cada materia. Não é de deferir-se, antes de tudo, plela razão principal e irremovivel de ser contrario á lei. Preceitua, com efeito, o art. 118 do regula. mento anexo ao decr. n. 24.102, de 10 de abril de 1934, que "não poderá prestar exame final na primeira epoca (dezembro) 0 aluno que não tiver comparecido a dois terços, no minimo, das aulas dadas em calda cadeira, cujo lexame pretenda fazer"; e tal preceito se acha repetido no art. 121, § unico, quando, tratando "das provas de habilitação", refere que "poderão inscrever-se para provas finais somente os alunos que tenham frequencia minima de dois terços das aulas dadas, da respetiva cadeira, e obtido, no minimo, nota cinco na media das provas parciais". 
"Não sendo, por isso, possivel deferir-se o pedido, por contrario a expressos textos de lei; e visto que a lei só se revoga, ou derroga, por outra lei - caso tambem não é de cogitar.se de nova lei sobre $o$ assunto, pois que tambem se acha ele plena e satisfatoriamente resolvido pela lei em vigor.

“O Brasil, tem sido dito em viarios tons, é um país de autodidatas. Estabeleceu-se, sem duvida por essa razão, o sistema da livre frequencia aos cursos juridicos. Nenhum estudante, matriculado na Faculdade de Direito, é obrigado a frequentar-lhe as aulas. Não está sujeito a pena alguma o que não puder ou não quizer ser guir-lhe os cursos. Sempre poderá fazer os seus exames e promover-se para os anos seguintes. Sempre foi assim. Não são poucos os bachareis formados sem terem frequentado os cursos academicos. Existe, para estes, uma epoca especial de exames, tradicional. mente. E' a segunda epoca. Duas, verdadeiramente, são as epocas de exames: a primeira - em dezembro; e a segunda - na primeira quinzena de fevereiro. Porque é assim, cuidou a lei, entretanto, de incentivar a frequencia dos cursos juridicos, concedendo vantagens a quantos fossem assiduos ás aulas, tais como:

“a) a de fazerem provas escritas, as duas provas parciais de cada ano e materia, sobre ponto sorteado "dentre os da parte explicada do programa";

"b) a de fazerem prova oral de arguição "sobre um ponto, tirado á sorte, dentre os do programa aficial dal cadeira", mas somente dentre "os pontos que tiverem sido explicados durante o ano".

“E' o que está díto nos arts. 131 , a) « 135, § 1, do regulamento.

"Podem fazer exames na primeira epoca os alunos matriculados que houverem assistido, no minimo, dois terços das aulas dadas em cada cadeira e obtido, no minimo, nota cinco na media das provas parciais.

"Os que, todavia, não comparecerem ás aulas ou não tiverem o minimo de comparecimento estabelecido pela lei; ou os que, tendo sido assiduos, não tiverem alcançado a media cinco nas provas parciais - poderão fazer os seus lexames na segunda epoca: na primeira quinzena de fevereiro. Haverá, está escrito no art. 125 do regulamento, uma segunda epocal de provas, na primeira quinzena do fevereiro, para os alunos:

“a) que não tenham podido inscrever-se na primeira epoca;

“b) que, na primeira epoca, tenham sido aprovados em todas as cadeiras do ano, menos uma.

"E o art. 126 declarou que a inscrição para exames de segunda epoca "independente de certidão de frequencia". Podem, conse- 
quentemente, faze-los, inscrevendo-se, os que deram mais de um terço de faltas ou os que nem mesmo uma só assistiram, por mera curiosidade. E os exames, nos termos do art. 127, consistirão em uma prova escrita e prova oral, para cada cadeira, obedecidas, no aplicavel, as disposições relativas ás provas de primeira epoca, com as seguintes modificações: a) versará o exame sobre todos os pontos constantes do programa de caida cadeira; b) as notas das provas parciais porventura realizadas pelo aluno no ano anterior não serão computadas no julgamento.

"Previu a lei, portanto, a hipotese de não desejarem os alunos frequentar os cursos juridicos, ou de não os poderem frequentar. A uns e outros permite realizem os seus exames na segunda epoca. A nenhum privou de oportunidade para a manifestaçã̃o de seus conhecimentos juridicos: deixou a cada um a liberdade da escolha do sistema de exames de sua predileção ou de sua conveniencia.

"Se se insistir em adotar o regime da frequencia livre, o chamado "ensino livre", entre nós já experimentado com tão singulares resultados, dever-se-á tambem, por coerencia, pugnar pela extinção da Universidade, recentemente criada e que foi o grande anhelo da mocidade de alguns anos atrás. Para que, com efeito, manter instituições universitarias inocuas, sem cursos, sem aulas, sem disciplina e sem cultura? Pois já não atingiu a Camara dos Dieputados a pretenção dos que tambem não desejam mais submeter-se às provas orais, que tantos talentos revelaram? Ainda bem que a Comissão de Educação e Cultura deu parecer contrario ao projeto de as suprimir: oxalá não venha o plenario a regeita-lo! Os iexames por decreto já produziram os seus maleficos efeitos. Moços matriculados nos cursos superiores, em numero surpreendente, são incapazes de escrever, sem erros gramaticais, as téses ditadas para as provas escritas! O semianalfabetismo é simplesmente alarmante. Convem denuncia-lo alto e bom som para que se esboce contra ele reação energica e necessaria. Dlestacam-se muitos estudantes magnificamente preparados e dispostos a fazer o seu curso juridico com assiduidade e eficencia. Serve, tambem, de demonstrar a possibilidade de um movimento salutar em prol do ensino universitario. De outra fórma será mais logico o fechamento das faculdades. Fechar-se-ão. Abrir-se-ão, em lugar delas, repartições especiais para as matriculas, no começo de cada ano; e, quando dezembro chegar, instalar-se-ão mesas especiais destinadas a dar ares de solenidade aos exames, transmudardos em simples formalidades. Será 1sso mais simples. Mais facil. Mais comodo. E, o que será de maior circunstância, muitissimo mais barato..." 
Vingou, felizmente, a bôa razão. As instruções, expedidas pelo sr. ministro da Educação, de acôrdo com as proposições do Conselhô Nacional de Educação, para cumprimento da lei chamada "das miedias", cortou a questão, esclarecendo que as promoções dos por ela beneficiados não dispensava a frequencia e outras exigencias das leis e regulamentos do ensino.

10. Não bastava o velho mosteiro franciscano em que funcionou, por mais de um seculo, a Faculdade de Direito, com as suas matriculas ano a ano aumentadas, para as suas necessidades atuais. Desprovido $d \theta$ instalações adequadas, sem as condições de higiene e de conforto, as refórmas, a principio projetadas e rexecutadas, para logo se mostraram insuficientes. A substituição da cobertura e dos soalhos, a limpeza e reparação da fachada, a modificação na disposição das salas de aulas e dos serviços administrativos, bastariam para a conservação do vasto edificio. Mas urgia amplia-lo ainda mais. Pensou-şe então em construir um edificio de tres pavimentos, com um grande anfiteatro para os atos solenes, outro para conferencias, salas para exames orais e escritos, etc. Propostas tais obras ao governo federal e dada a cincunstancia de que seriam elas custeadas pelos soldos disponiveis que a Faculdade de Direito então possuia, em dinheiro e em apolices, foram autorizadas e iniciadas em 15 de dezembro de 1932. Contratou-se o serviço de administração delas com Severo \& Vilares, cuja proposta foi preferida, em 2 de fevereiro de 1932, mediante uma remuneração correspondente a $6 \%$ do custo real das obras, assumindo eles, ademais, outras obrigações e aceitando outras condições, expressas nas clausulas contratuais. Todos os serviços e fornecimentos foram ajustados, salvo alguns de pequena monta, por concurrencia administrativa.

Ao assumir, o sinatario desta exposição, a diretoria da Faculdade de Direito, teve a preocupação de fazer apressar as obras de construção do novo pavilhão. Prosseguiram mais rapidamente sob slia fiscalisação direta e continua, contando com a boa vontade dos administradores sempre solicitos. Tratou de fazer, naquele pavilhão, a instalação provisoria da diretoria, da secretaria, da tesouraria, do almoxarifado. Assim, ficaram, ao encerrar-se o ano de 1934, a secretaria, a tesouraria e almoxarifado localisados no andar terreo com frente para a rua do Riachuelo. No andar terreo superior, que dá para as arcadas do claustro, em parte restauradas, ficaram os dois grandes anfiteatros, com capacidade para duzentas e poucas pessoas sentadas comodamente, que receberam as denominações de "Sala João Mendes Junior" um e o outro de "Sala Barão de Rama. lho". No primeiro andar instalou-se, amplamente, a biblioteca, 
com duas salas de leitura, salas de administraçã̉o e livraria, esta num amplo e magestoso salão provido de estantes de aço, em tres andares superpostos, mais a oficina de encadernação. No mesmo andar se acha portaria e, tambem, ali se encontra a Sala das Be. cas. 0 grande salão destinado ao museu academico foi aproveitado para sala de aulas. No segundo andar instalaram-se tres salas para aulas, a Congregação, a Diretoria, mais a Reitoria e a Secretaria da Universidade de (S. Paulo. Aproveitou-se, no mais que foi possivel, todo o mobiliario, instalações, cortinas, bancos, catedras e tudo o mais que já existia. Conservar melhonando foi o lema adotado e cumprido.

Com essas medidas provisorias, vai funcionar a Faculdade de Direito, neste ano de 1935, no predio novo, o que permitiu iniciar-se a idemolição da frente do velho edificio, que dá para o largo de São Francisco e de sua fachada lateral para a rua Cristovão Colombo. Quando estas linhas são escritas, vai adiantada a demolição, de que se não fala sem uma profunda nota de nostalgia. Vai, naquele lugar sagrado e historico, erguerse um monumental edificio de quatro andares, digno do futuro radioso da Universidade de S. Paulo.

Ficará por algum tempo ainda a servir a parte do velho edificio, que fica no encontro da rua Cristovão Colombo com a rua Ria. chuelo, e que era ocupada, no andar superior, pelas duas salas que foram da biblioteca, e, no andar inferior, pela sala que, por muito tempo, se chamou “da mumia" e na qual prelecionou o saudoso professor Amancio de Carvalho.

$O$ custo das obras feitas estão orçadas em 1.900 contos de réis. Importavam, com o material e mobiliario fornecidos e faturados, em 31 de dezembro de 1934, exatamente, em Rs. 1.575:983\$051, dos quais, naquela data, tinham já sido pagos e liquidados Rs. ....... 1.053:422\$075. Aguardavam pagamento faturas na importancia de Rs. 522:560\$976. Para fazer face a esses pagamentos, mais aos das faturas ainda não apresentadas, contava a Faculdade de Direito com o saldo de contas correntes a prazo fixo em bancos, com as importancias por ela adiantadas ao Tesouro do Estado e com os valores de mil tantas apolices federais e estaduais, como tudo e melhor se verifica pela leitura do relatorio anexo da tesouraria.

O novo predio da Faculdade de Direito, fique bem patente, até agora, foi construido e continuará a construir-se, com as rendas da Faculdade de Direito, economia de muitos annos, cuidadosamente conservada para a realisação deste grande empreendimento, de que se orgulharão as gerações que para ele contribuiram e ainda contribuirão. 
Está o governo do Estado de São Paulo, no entanto, animado do proposito de colaborar para que as obras prossigam sem solução de continuidade de modo a terem a Faculdade de Direito e a Universidado de São Paulo instalação condigna e monumental.

11. Em vista das disposições do decreto federal $\mathrm{n}$. 24.102, de 10 de abril de 1934, e do decreto estadual n. 6.429, de 9 de maio de 1934, o orçamento da receita e da despesa da Faculdade de Direito teve de abranger tres partes distintas:

a) o orçamento geral das despezas a cargo do governo do Es. tado de São Paulo;

b) o orçamento geral das despezas a cargo do governo da União;

c) o orçamento interno da Faculdade, compreendendo rendas internas e despezas custeadas pela tesouraria desta.

Acontecerá isso ainda por muito tempo. Assegurou o decreto federal de transferencia ao Estado ide São Paulo da Faculdade de Direito a professores e funcionarios os direitos e as vantagens das leis federais, inclusivé o pagamento dos respetivos vencimentos pelo Tesouro Federal. Isso, quanto aos então em exercicio de seus cargos. Os nomeados posteriormente tiveram e têm os seus direitos e deveres regulados pelas leis estaduais e os respetivos vencimentos a cargo do Tesouro do Estado.

Num dos relatorios anexos se encontra o desenvolvimento desses orçamentos, aprovados pelas leis orçamentarias da União e do Estado, com todas as suas verbas perfeitamente discriminadas.

Contribuindo, pela primeira vez, para a manutenção da Faculdade de Direito, a despeito da grande parte da contribuição federal, o governo do Estado lhe concedeu uma dotação de Rs........ $886: 250 \$ 000$, quasi o dobro da federal. Como se verá das discriminações, a mór parte dela é destinada ao pessoal, cujo numero foi aumentado e cujos vencimentos foram aumentados tambem. Estabeleceu-se, tambem, a remuneração para os professores do curso de doutorado, não contemplados no orçamento federal.

12. Prevalece entre a maioria dos professores o conceito da conveniencia da supressão do curso de doutorado. Foi esse sempre assunto em debate e que provocou os mais divergentes pareceres. Destinou-o o decreto de sua creação "especialmente á formar ção dos futuros professores de direito, na qual é imprescindivel abrir aos estudos de alta cultura, dispensaveis áqueles que se desfinam apenas á pratica do direito. O curso de doutorado se dis- 
tribue, naturalmente, em tres grandes divisões: a do direito privado, a do direito publico constitucional e a do direito penal e ciencias criminologicas". Dando-lhe essa alta finalidade, deixou o governo, entretanto, de ministrar-lhe os recursos necessarios para o seu funcionamento regular, exigindo trabalho gratuito dos que tomassem sobre si as responsabilidades do ensino de suas materias. Não lhe traçou a estrutura em linhas marcantes, nem deu objetivo util á sua finalidade. Se devia o curso de doutorado ser o prepatorio dos futuros professores de direito, algumas vantagens devia tambem ter concedido aos que o ultimassem.

O que é certo, entretanto, é que o curso de doutorado não foi procurado pelos candidatos ao professorado juridico. Nele se inscreveram alguns estudantes e inumeros bachareis, não poucos desejosos de obter o titulo doutoral de que todos usam.

Varios motivos, entretanto, lhe impediram o funcionamento regular a proficuo. Mal iniciado em 1932, interrompeu-o a revolução constitucionalista. Vieram depois as aprovações por decreto. Substituindo-se os professores, todos de emprestimo, e importando isso, sem duvida, na variação das diretrizes doutrinarias; a falta de obrigatoriedade da frequencia; as interrupções das aulas; e outros fatores varios - deram em resultado a ineficiencia do curso de doutorado. Nele se apresentaram, por certo, espiritos bem formados, que deram rendimento brilhante. Mas isso, é de confessar, mais pelo tratarıse de espiritos já amadurecidos no estudo e na observação do fenomeno juridico do que pelos efeitos do proprio curso.

Incorporando a Faculdade de Direito á Universidade de São Paulo, procurou o governo do Estado eliminar um dos males do curso de doutorado e deu-lhe professores fixos, nomeados para o ensino de cada uma de suas disciplinas. Mas nem todos os males desapareceram. Predomina, por isso, entre os proprios professores do curso de doutorado a idéia de que deve ser facultativa a cada Universidade a instituição do curso de doutorado na sua Faculdade de Direito, de modo a que o Conselho Universitario lhe dê a organisação adequada, no ou nos momentos em que julgar conveniente pollo em funcionamento.

Depende isso, entretanto, de medida legislativa do poder competente federal. Nada obsta a que a sugestão seja aqui lançada, para ser renovado o estudo da materia e encaminhado ao Conselho Nacional de Educação para quando tiver ele de elaborar o plano nacional de educação referido pela carta constitucional de 16 de julho de 1934. 
13. Consigno, ao terminar estas observações, decorrentes dos relatorios anexos, fornecidos pelas repartições administrativas da Faculdade de Direito, um elogio a todos os que nelas trabalham: prestaram-me auxilio relevante, em epoca anormal, de trabalho acrescido pela mudança para a parte do novo edificio, em que agora funcionam.

14. Inicia-se, pois, uma era nova para a secular Faculdade de Direito: dei-lhe, no semestre final de 1934, em que a dirigi, toda a minha dedicação. Não lha regatearei nunca para que ela prossiga na sua faina historica e gloriosa.

São Paulo, janeiro de 1935.

WALDEMAR FERREIRA. 


\section{ANEXO N. 1}

\section{Relatorio dos serviços da Secretaria no ano letivo de 1934}

\section{DIRETORIA}

Exerceram a Diretoria durante o ano de 1934 :

- 0 Dr. Candido N. Nogueira da Motta, na qualidade de membro do Conselho Técnico Administrativo, mais antigo no magisterio, no impedimento do diretor efetivo, Dr. José de Alcantara Machado de Oliveira, com assento na Assembléa Nacional Constituinte, de $10^{\circ}$ de janeiro a 15 de julho;

- O Dr. Luiz Barbosa da Gama Cerqueira, no periodo decarrido de 9 de março a 6 de abril, duranto o impedimento do $\mathrm{Dr}$. Candido N. Nogueira da Motta, por motivo de goso de férias regulamentares;

o Dr. Waldemar Martins Ferreira, eleito pelo Conselho Técnico Administrativo, de acôrdo com o art. 24 do decr. $n .^{\circ} 6.429$ de 9 de maio de 1934 e 70 do decr. 6.533 de 4 de julho do mesmo ano, para o cargo de Vice-Diretor e, em seguida, empossado pelo mesmo Conselho, exerceu a Diretoria de 16 de julho a 31 de dezembro.

\section{CONSELHO TÉCNICO ADMINISTRATIVO}

Para membros deste Conselho, foram nomeados pelo Governo do Estado, nos termos do Regulamento em vigor, os professores: Drs. Vicente Ráo, Francisco Morato, Mario Masagão, Waldemar Ferreira, Candido N. Nogueira da Motta e Gabriel de Rezende Filho.

- 0 Conselho celebrou durante $o$ ano 23 reunióes. 


\section{CONGREGAÇÃOO}

A Congregação reuniu-se nos dias 23 de janeiro, 21 de fevereiro, 17 de março, 30 de abril, 9,15 e 29 de maio, 20,26 e 31 de julho, 7 de agosto, 11 de setembro, 4, 18, 22, 29 de outubro, 7, 14, 17 e 20 de novembro e 10 de dezembro.

\section{CORPO DOCENTE}

Curso de Bacharelado: Ao iniciar-se o ano letivo, o corpo docente do Curso de Bacharelado desta Faculdade estava constituido dos seguintes professores: Drs. José de Alcantara Machado de Oliveira, Candido N. Nogueira da Motta, Luiz Barbosa da Gama Cerqueira, Raphael Corrêa de Sampaio, Manoel Pacheco Prates, Theophilo Benedicto de Souza Carvalho, José Augusto Cesar, José Joaquim Cardoso de Mello Netto, Spencer Vampré, Francisco Morato, Waldemar Ferreira, Braz de Souza Arruda, Antonio de Sampaio Doria, Vicente Ráo, Ernesto Leme, Mario Masagão e Gabriel de Rezende Filho.

Curso de Doutorado: Para professores deste curso foram nomeados por decr. de 8 de julho, do Governo Estadual, os srs.:

Dr. Vicente Ráo (Direito Publico);

Dr. Luiz B. da Gama Cerqueira (Criminologia);

Dr. A. de Sampaío Doria (Economia e Legislação Social);

Dr. Waldemar Ferreira (Historia do Direito Nacional);

Dr. J. J. Cardoso de Mello Netto (Ciência das Finanças).

- O Dr. Sylvio Portugal, desembargador da Corte de Apelação do Estado, foi contratado para reger a cadeira de Direito Civil Comparado;

- O Dr. Francisco Morato regeu a oadeira de Direito Publico, em substituição ao Dr. Vicente Ráo;

- O Dr. Braz de Souza Arruda regeu a cadeira de Ciência das Finanças, durante o impedimento do Dr. Cardoso de Mello Netto e a de Direito Publico, em substituição ao Dr. Francisco Morato, em virtude de indicação da Congregação;

- O Dr. Mario Masagão, indicado pelo Conselho Técnico Administrativo, regeu a cadeira de Filosofia do Direito, a ser provida por concurso. 


\section{CONCURSO}

A 16 de novembro, perante a respectiva banca examinadora, na qual tomaram parte os professores Manoel Cicero Peregrino da Silva, Hahnemann Guimarães e Estevam Pinto das Faculdades de Direito do Rio de Janeiro e de Minas Geraes, eleitos pelo Conselho Técnico Administrativo e professores Spencer Vampré e Mario Masagão, eleitos pela Congregação, realizou-se o concurso para provimento da cadeira de Direito Romano, ao qual se apresentou o unico candidato inscrito, Dr. Alexandre Correia que, por unanimidade de votos, foi declarado habilitado no dia 19 do mesmo mez, depois de realizadas todas as provas do refierido concurso.

\section{NOMEAÇÕES}

O Dr. Honorio Fernandes Monteiro, docente livre, para catedratico de Direito Comencial, por decr. de 3 de julho, do Governo Estadoal;

O Dr. Ernesto Leme, docente livre, para catedratico de Direito Comercial, por decr. de 19 de fevereiro;

o Dr. Alexandre Correia, para catedratico de Direito Romano, por decr. de 5 de dezembro;

O Dr. Sebastião Soares de Faria, habilitado em concurso realizado nesta Faculdade, em 1933, foi nomeado por portaria de 10 de dezembro, do Snr. Diretor da Faculdade, para docente livre de Direito Comercial.

\section{COMISSIONAMENTOS}

O Dr. Luiz Barbosa da Gama Cerqueira foi designado para, em comissão, organizar o projeto de Codigo do Processo Penal, junto ao Ministerio da Justiça e Negocios Inteniores;

O Dr. A. de Sampaio Doria, por áto do Governo do Estado, de 28 de julho, foi posto em comissão junto ao Ministerio da Justiça;

O Dr. Spencer Vampré exerceu comissão junto à Diretoria Geral de Educação, de $10^{\circ}$ de janeiro a 28 de fevereiro.

\section{CONTRATOS}

o Dr. Sylvio Portugal foi contratado para reger a cadeira de Direito Civil Comparado, do Curso de Doutorado. 


\section{APOSENTADORIAS}

Por decreto do Chefe do Governo Provisorio da Republica foi aposentado, a 2 de janeiro, o Dr. João Braz de Souza Arruda, catedratico de Filosofia do Direito;

Nos termos do art. $170, n^{\circ} 3$ da Constituição Federal, foi aposentado, a $10^{\circ}$ de outubro, o catedratico de Direito Civil, Dr. Manoel Pacheco Prates.

\section{LICENÇAS}

O Dr. Luiz Barbosa da Gama Cierqueira gosou 20 dias de licença, a contar de 24 de julho.

\section{SUBSTITUIÇÕES}

O Dr. Honorio Fernandes Monteiro, de $10^{\circ}$ de janeiro a 16 de Março, regeu a cadeira de Direito Comercial, vaga com o falecimento do respectivo catedratico, Dr. Octavio Mendes, e a cadeira de Economia e Legislação Social, do 2..$^{\circ}$ ano do Curso de Doutorado, em subsitituição ao professor efetivo, Dr. Antonio de Sampaio Doria;

o Dr. Antonio Ferreira de Almeida Junior, docente livre, substituiu ao Dr. José de Alcantara Machado, na regencia da cadeira de Medicina Legal, do $4 .^{\circ}$ ano do Curso de Bacharelado;

o Dr. Noé de Azevedo, docente livre, substituiu ao Dr. Candido $N$. Nogueira da Motta, da cadeira de Direito Penal, do $3 .^{\circ}$ ano do Curso de Bacharelado, de 6 de março a 9 de abril e ao Dr. Luiz Barbosa da Gama Cerqueira, catedratico de Direito Penal, na regencia das $10^{\mathrm{a}}$ e 2." turmas do $20^{\circ}$ ano do mesmo curso;

O Dr. Manoel Francisco Pinto Pereira, docente livre, regeu a cadeira de Economia Politica e Ciência das Finanças, do $10^{\circ}$ ano do Curso de Bacharelado, em substituição ao Dr. José Joaquim Cardoso de Mello Netto;

o Dr. Braz de Souza Arruda, substituiu ao Dr. José Joaquim Cardoso de Mello Netto, na regencia da cadeira de Ciência das Finanças, do $2 .^{\circ}$ ano do Curso de Doutorado;

Ainda, o Dr. Braz de Souza Arruda, substituiu ao Dr. Francisco Morato, na regencia da cadeira de Direito Publico, do Curso de Doutorado;

O Dr. Francisco Morato substituiu ao Dr. Vicente Ráo, na regencia da cadeira de Direito Publico, do $1 .^{\circ}$ ano do Curso de Doutorado; 
O Dr. Spencer Vampré substituiu ao Dr. Antonio de Sampaio Doria, na regencia da cadeira de Direito Constitucional, 1." turma, do 2. ano do Curso de Bacharelado;

o Dr. Jorge Americano, substituiu ao Dr. Vicente Ráo, na regencia da cadeira de Direito Civil, do $20^{\circ}$ ano; regeu a de Direito Civil, do 3. ano, vaga com a aposentadoria do Dr. Manoel Pacheco Prates, respectivo catedratico; e a turma desdobrada da de Direito Civil, do $4 .^{\circ}$ ano, todas do Curso de Bacharelado;

o Dr. Candido N. Nogueira da Motta, substituiu ao Dr. Luiz Barbosa da Gama Cerqueira, na regencia da cadeira de Criminologia, do $10^{\circ}$ ano, do Curso de Doutorado.

\section{CORPO DISCENTE}

De 16 de fevereiro a 10 de março, realizaram-se os exames vestibulares.

Fizeram parte da banca examinadora os Drs. Candido N. Nogueira da Motta, Raphael Corrêa de Sampaio, Spencer Vampré, Mario Masagão, Honorio Fernandes Monteiro e Gabriel José Rodrigues de Rezende Filho.

Inscreveram-se para os exames vestibulares 325 candidatos, havendo o seguinte resultado d'aquele exame:

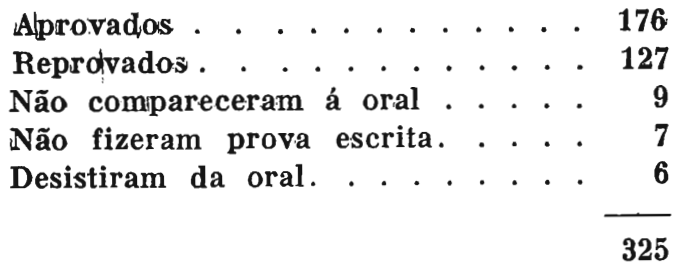

Na segunda quinzena de março, realizaram-se os exames de 2:" época do Curso de Bacharelado, tendo sido este o resultado do mesmo:

\section{$1 .^{\circ}$ Ano}

Inscritos 6 .

Introd. Econom.

\begin{tabular}{llll} 
Aprovados. . . . . . . . . & 6 & 3 \\
Já fizeram esta materia & $\ldots$ & - & 2 \\
Aprovados por média. . . & - & 1 \\
\hline & & -6
\end{tabular}


2. ANo

Inscritos 21

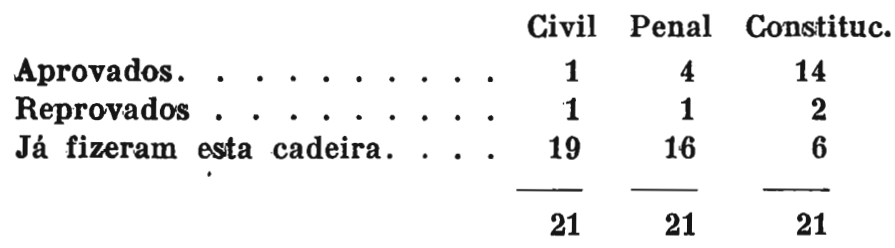
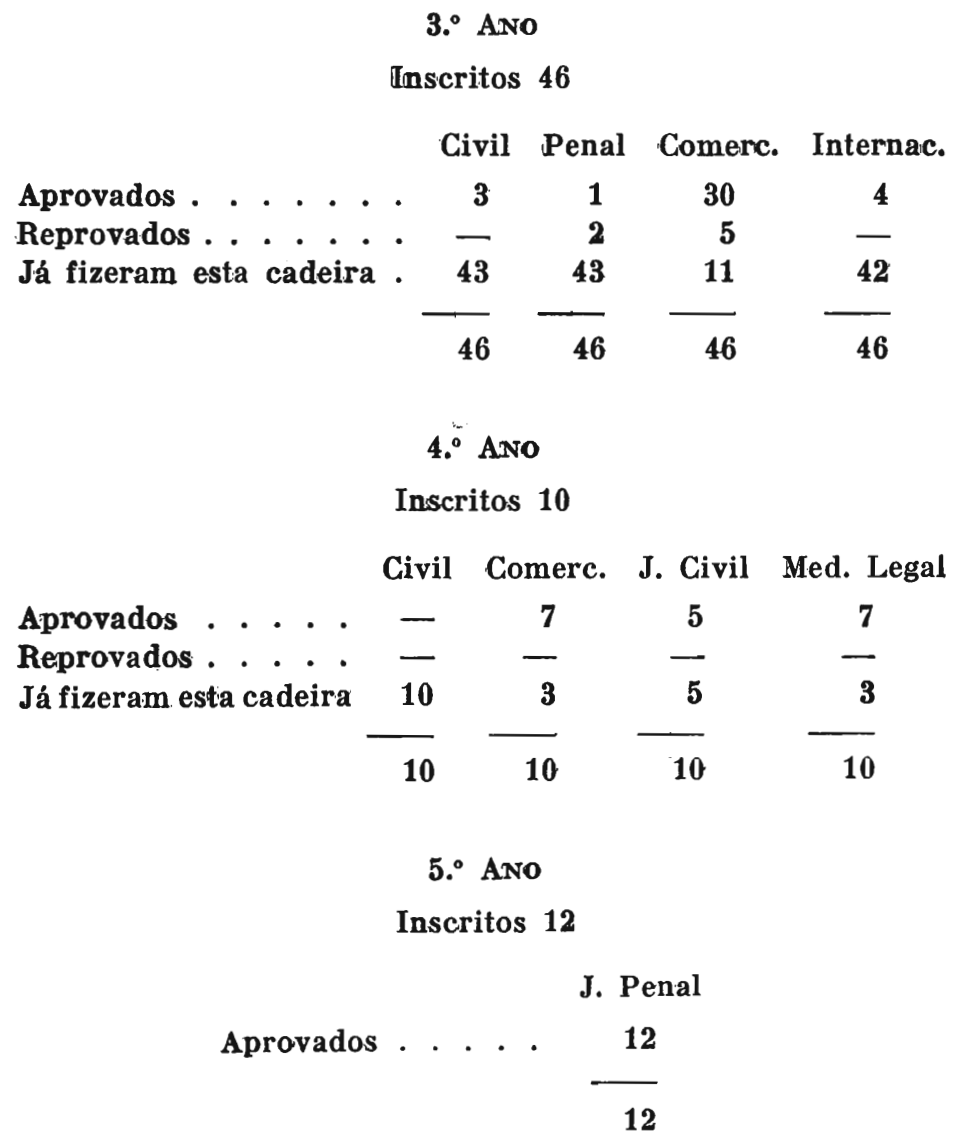


\section{CURSO DE BACHARELADO}

Exames de 1.` época.

$10^{\circ}$ Ano

Inscritos 345

Introd. Econom.

\begin{tabular}{|c|c|c|}
\hline Aprovados & 121 & \\
\hline Reprovados & 21 & 19 \\
\hline Não alcançaram média & 47 & 14 \\
\hline Promovidos por médias & 77 & 155 \\
\hline Não promovidos & - & 10 \\
\hline Não se inscreveram & 70 & 7 \\
\hline Não se inscreveram na cadeira. & - & \\
\hline Não compareceram à oral . . & 3 & \\
\hline Com exame feito . . & 1 & - \\
\hline Com dependencia de cadeira. & 1 & - \\
\hline & 345 & \\
\hline
\end{tabular}

2. ANo

Inscritos 185

\begin{tabular}{|c|c|c|c|}
\hline & Civil & Penal & Constitu \\
\hline Aprovados . . & 25 & 16 & 43 \\
\hline Reprovados & 1 & - & - \\
\hline Não alcançaram média & 14 & 3 & 3 \\
\hline Promovidos por médias . . & 87 & 105 & 14 \\
\hline Não promovidos & 8 & 12 & 8 \\
\hline Não se inscreveram & 45 & 45 & 45 \\
\hline \multicolumn{4}{|l|}{ Não se inscreveram } \\
\hline na cadeira. & 1 & 1 & 10 \\
\hline Matricula cancelada . . . & 1 & 1 & 1 \\
\hline Falecido i. . . . & 1 & 1 & 1 \\
\hline \multirow[t]{2}{*}{ Não compareceram à oral. } & 2 & 1 & - \\
\hline & 185 & 185 & $3 \check{2}$ \\
\hline
\end{tabular}




\section{3..$^{\circ}$ ANo}

Inscritos 273

\begin{tabular}{|c|c|c|c|c|}
\hline & & Civil & Penal & Comerc. \\
\hline Aprovados . . . . . . & . & 2 & 23 & 48 \\
\hline Reprovados.. . . . . . & . & 1 & 6 & 3 \\
\hline Não alcançaram média. & . . & - & 5 & 101 \\
\hline Promovidos por médias & . . & 82 & 145 & 37 \\
\hline Não promovidos . . . . & . . & 113 & 15 & 2 \\
\hline Não se inscreveram . . . & . & 72 & 72 & 72 \\
\hline $\begin{array}{l}\text { Não se inscreveram } \\
\text { nesta cadeira.... }\end{array}$ & . & - & 3 & 8 \\
\hline Não fizeram prova escrita & . . & 3 & 2 & 1 \\
\hline Não compareceram à oral & . & 一 & 2 & 1 \\
\hline & & 273 & 273 & 273 \\
\hline
\end{tabular}

$4 .^{\circ}$ ANo

Inscritos 256

Civil Comerc. Jud. Civil Med. Legal

$\begin{array}{llllll}\text { Aprovardos . . . . . . . } & 18 & 34 & 59 & 13\end{array}$

Reprovados. . . . . . . 1014 - 11

$\begin{array}{llllr}\text { Não alcançaram média . } & 2 & 10 & 2 & 14\end{array}$

$\begin{array}{lllll}\text { Promovidos por médias . } & 128 & 84 & 73 & 119\end{array}$

$\begin{array}{llllll}\text { Não promovidos . . . . } & 7 & 4 & 2 & 5\end{array}$

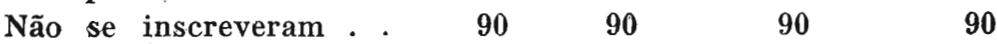

Não se inscreveram

$\begin{array}{llllll}\text { nesta cadeira . . . . . . } & 10 & 34 & 28 & 13\end{array}$

Não compareceram à oral $\quad-\quad \ldots \quad-\quad 2 \quad 1$

$\begin{array}{llll}256 & -\frac{1}{256} \quad \frac{1}{256}\end{array}$

NUMERO DOS ALUNOS MATRICULADOS NOS DIVERSOS ANOS DO

CURSO DE BACHERALADO . . . . . . . . . . . 1.059

CURSO DE DOUTORADO

No $10^{\circ}$ ano.... 26

No $20^{\circ}$ ano .... 15 


\section{PESSOAL ADMINISTRATIVO}

Registaram-se no decorrer do ano os fatos seguintes:

- o bacharel Julio Joaquim Gonçalves Maia esteve em goso de licença de 10 de janeiro a 24 de julho;

- por ato de 25 de julho, do Governo do Estado, foi a bacharel Julio Joaquim Gonçalves Maia posto em comissão junto à Secretaria da Educação e Saúde Publica, sem prejuizo dos seus vencimentos;

- o bacharel Julio de Barros, idesignado por portaria desta Faculdade, exerceı as funções de secretario interino, de $\mathbf{1 0}$ de janeiro a 28 de maio;

- o ISnr. Flavio Mendes, auxiliar de secretario (chefe de secção), foi designado por portaria do Snr. Diretor desta Faculdade para, interinamente, exercer as funções de secretario, a partir de 29 de maio;

- ao continuo Milton Milfont foram concedidos seis mezes de licença, a contar de 22 de dezembro, tendo sido indicado para substitui-lo o servente Luiz Nazareth, que entrou em exercicio na mesma data.

\section{APOSENTADORIAS}

Nos termos do art. 170 n..$^{\circ} 3$ da Constituição Federal, foram aposentados, por contarem mais de 68 annos de idade, o bacharel Julio Joaquim Gonçalves Maia, secretario, e o amanuense Antonio José de Freitas.

\section{NOMEACX̄ES}

Em virtude do decreto 6429, de 9 de maio de 1934, o quadro de funcionarios da Faculdade foi alterado, ficando constituido do seguinte pessoal:

AUXILIAR DO SECRETARIO (CHEFE DE SECÇÃO)

Flavio Mendes

CHEFE DE SECÇÃO

Raul Assumpção Sampaio

\section{TESOUREIRO}

Heitor de Souza Lima

CONTADOR

Cassio José de Toledo 
CHEFE TÉCNICO DA BLBLIOTECA

Leonel Vaz de Barros

AUXILIAR TÉCNICO DA BIBLIOTÉAA

José Fernandes Moreno

\section{PRIMEIROS ESCRITURARIOS}

Bacharel Julio de Barros

João de Campos

\section{SEGUNDOS ESCRITURARIOS}

Antonio José de Freitas

Frederico Baptista de Souza

Agilulpho Candido Dias

Milton Penteado

\section{TERCEIROS ESCRITURARIOS}

Herculano iSalgado de Mello

Geraldo da Silva Leite

João Pedro de Assis Pacheco

Bacharel Durval Rebouças

\section{QUARTOS ESCRITURARIOS}

Claro Augusto de Miranda

Pedro Athanazio da Silva

Adolpho Schmidt Junior

Miguel Rogerio de Freitas

\section{PORTEIRO}

Pedro Dias da Silva

\section{BEDEIS}

Sebastião Ignacio da Silva

Abilio Pereira de Oliveira

Argemiro Pontes

José Martinho de Moura Baptista

Vicente Personal

Edgard Sylvestre

Elias Appolinario Rodrigues

José Epaminondas de Oliveira

Jeronymo Teixeira da Silva (interino) 


\section{SECRETARIA}

Papeis Entrados: - 3.772

Papeis protocolados durante o ano . 3.772

Requerimentos diversos . . . . . 816

" do curso . . . . . . . 959

Outros papeis . . . . . . . . . . 1.987

Oficios diversos . . . . . . . . . . .

" á Dir. Geral de Educação, remetendo o historico da vida escolar de bachareis . . . . . . . . . . 246

Oficios á Delegacia Fiscal . . . . . $\quad 38$

Correspondencia oficial com os professores e funcionarios . . . . . . 109

Correspondencia com o Governo do Estado.. . . . . . . . . . 54

Editais, avisos e publicações varias . 49

A Secretaria expediu, durante o ano, 203 cartas de bachareis, 3 de doutores e 856 certidões.

S. Paulo, 31 de Dezembro de 1934.

FLAVIO MENDES

Secretario Interino 


\section{ANEXO N. 2}

\section{Relatorio dos serviços, movimento e mudança da Bi- bliotéca, em 1934}

Exmo. Snr. Diretor da Faculdade de Direito da Universidade de S. Paulo.

Dando cumprimento à determinação de V. Excia., tenho a honra de submeter-lhe o Relatorio da atividade, movimento e modificações apresentados no decorrer do ano de 1934, pela Bibliotéca desta Faculdade.

Os serviços da Biblioteca fizeram-se normalmente durante o ano de 1934, até o mez de outubro, em que se iniciou a mudança das suas coleções para a nova livraria. A partir desse mês, até meiados de dezembro, foi necessario suspender parte do expediente e a consulta, dada a impossibilidade de se manter essa atividade simulta. neamente com a retirada, transporte e recolocação dos volumes.

\section{MUDANÇA}

Quasi terminadas as obras da parte do novo edificio da Faculdade, destinada à Biblioteca, iniciou-se, na epoca acima referida, a mudança dos livros. Foram eles distribuidos, por tamanhos, pelas estante de aço que, em numero de 13 grupos de 3 andares e 8 de dois andares, guarnecem respectivamente as paredes e o ambito central do amplo salão da nova livraria.

Esses grupos, que comportam, nos lateraes, variado numero de estantes cada um, e nos centraes, 16, foram designados, da direita para a esquerda, pelas letras maiusculas, de A a U. As estantes de cada grupo foram, em cada grupo, marcadas por algarismos, 1, 2, $3,4,5$, etc. $E$ as prateleiras receberam os numeros de 10 a 19 , para 
as do $1 .^{\circ}$ andar; 20 a 29 , para as do $20^{\circ}$ e 30 a 39 , para as do $3 .^{\circ}$. Com esse artificio, o algarismo da dezena do numero designativo das prateleiras já indica tambem o andar, reduzindo-se assim e simplificando as cotas a mencionar nas fichas dos catálogos, para indicacação da colocação dos volumes. Assim, uma ficha que tenha a cota

$$
\text { D. } 1-25-15
$$

indica que o volume correspondente está colocado no $4 .^{\circ}$ grupo de estantes, a partir da esquerda de quem entra para a livraria, pela porta de comunicação com a sala de expediente; que nesse $4 .^{\circ}$ grupo, o volume deve ser procurado na estante n. 1 (D. 1); que essa estante se acha no $2 .^{\circ}$ andar (25) e, finalmente, que nessa prateleira . $^{\circ}$ 25, o volume é o $15 .^{\circ}$ (15) a partir da esquerda de quem olha para a estante.

Essa convenção tem-se revelado pratica e eficaz, na busca dos volumes pelos funcionarios encarregados desse serviço, os quais gastam assim o minimo tempo no atender aos pedidos.

Distribuidos os livros da Biblioteca pelas estantes da nova livraria, verificou-se que a capacidade destas excede largamente ao numero dos volumes atualmente existentes, que é de cerca de 41 mil; assim, poderão ser alojados ainda cerca de 20 mil volumes novos, sem nenhuma modificação prévia nas atuais instalações.

A sala de leitura acha-se instalada no local para isso previsto na projeção do novo edificio, grande aposento fartamente arejado por amplas janelas em tres faces; ha ahi 25 globos eletricos, o que tudo faculta perfeita iluminação diurna e noturna, para que a consulta possa ser distribuida em varios periodos de dia e de noite. Oito mesas grandes aí oferecem lu'gar para 132 leitores comodamente instalados, ficando ainda espaço para uma dezena de mezinhas individuaís para os consulentes que as prefiram. Alèm disso, junto da livraria, foram reservadas 4 celas, bem arejadas, cada uma com sua carteira e cadeira para os consultantes que tenham algum trabalho de pesquiza nas coleções da Biblioteca e que para isso necessitem absolutos socego $\mathrm{e}$ isolamento.

Uma pequena sala contigua ao salão de leitura foi ocupada com as coleções de revista em vias de publicação e serve para a sua consulta bem como para a leitura de jornais. Essa parte da instalação ressente-se da exiguidade do espaço que lhe foi destinado, sendo de recomendar que de futuro se lhe destine mais amplo local.

Idêntica circunstância ocorre com a localização das secções técnicas e de expediente da Biblioteca. $O$ aposento que para isso foi reservado revelou-se acanhadissimo, não oferecendo o espaço necessario para as mesas dos funcionarios, estantes, cadeiras, etc., e 
largueza par aos consultantes que hajam de manusear os catalogos, cujos ficharios têm necessariamente de ser ai colocados.

Uma galeria praticada nesse aposento, com o fim de remediar a essa exiguidade, mostra-se de minguada serventia, devido à dificuldade do acesso que lhe dá uma empinada, estreita e incomoda escadinha, e ao escasso arejamento dêsse ambiente, onde o trabalho se torna, por isso, mui penoso.

\section{MOVIMENTO}

O movimento de consultas da Biblioteca durante o ano de 1934 (excetuando os mezes de Novembro e Dezembro em que estiveram suspensas em consequencia da -mudança) foi a seguinte:

De estudantes da Faculdade..........
De pessoas estranhas à Faculdade......
Leitores de jornais...................
Consultas por correspondência........

Num total de............. 16.240 consultas

Esses consultantes manusearam um total de 14.072 obras, em 19.870 volumes, cuja especificação e classificação se deparam no mapa submetido á apreciação dessa Directoria. Por êsse mesmo mapa se verifica que deram entrada na Biblioteca 2.021 obras, das quaes 305 por compra, 1.272 por doação e 444 por permuta com exemplares de duplicatas existentes. No mesmo documento se regista a encadernação de 1.349 volumes e a reconstituição de 416, num total de 1.765 . Com exceção de 12 volumes, todas as reconstituições foram feitas na pequena oficina anexa à Biblioteca, onde tambem se executaram 827 das encadernações.

\section{REMARCAÇÃOO DOS VOLUMES}

Removidos os livros da Biblioteca da antiga para a nova livraria, foi necessario proceder-se à remarcação quanto à colocação em as novas estantes, tanto nas lombadas dos volumes como nas fichas respectivas. Esse serviço, que deu azo a uma revisão geral do catalogo, está sendo feito pela secção técnica, e alguma morosidade que acaso apresente se deve à falta de um datilógrafo para a reconfecção das inumeras fichas deterioradas e das que por outros motivos foram julgadas carecedoras de substituição.

Por não se acharem, pois, todos os volumes e respectivas fichas remarcadas, a consulta ainda não tem podido ser atendida inte- 
gralmente. 0 mesmo inconveniente se refléte no movimento das consultas bibliograficas, cujo aviamento e escrita à maquina distraíriam o auxiliar técnico de atividades, no momento, mais urgentes.

\section{PESSOAL}

Entre as modificações de ordem administrativa introduzidas na Biblioteca por ocasião da passagem da Faculdade, do regime Federal para o Estadoal, poder-se-á enquadrar a nomeação do Snr. Sergio Milliet da Costa e Silva para o cargo de secretario da Reitoria da Universidade de São Paulo, com o que ficou vago o lugar de "chefe técnico" desta Bibliotéca, vindo-o eu preencher por ato de 5 de julho de 1934 e posse a 10 do mesmo mês o ano. Servirá êsse registo para justificar a transcrição que óra faço, do que, em rela. torio dessa ultima data, disse o meu antecessor quanto à classificação, atribuições e eficiência dos funcionarios a cujo cargo se acham os serviços da Bibliotéca:

Diz o citado relatorio:

"Cabe atualmente ao Chefe Técnico":

1) controlar a classificação e catalogação

2) controlar a secção de consulta

3) controlar a secção de expediente

4) responsabilizar-se pelas permutas de livros

5) comprar novas obras

6) escolher os volumes a serem encadernados fóra

7) organizar as estatisticas

8) assinar a correspondência

9) promover o intercambio de publicações com as bibliotécas e universidades estrangeiras.

Além dessas atribuições, como Secretario da Comissão de Redação da Revista, cabe-lhe distribuir a materia a ser publicada, escolhe-la, submetendo-a à Comissão, corrigir as provas e velar pela regularidade da publicação.

Muitas dessas atribuições, como é facil de vêr, são de ordem exclusivamente técnica. Um leigo não poderia cumprir com eficiencia tudo aquilo que ficou aféto ao Chefe Técnico. Entretanto, já prevendo que no futuro a organização dada à Bibliotéca viria a sofrer modificações, que seria possivel a nomeação de chefes não técnicos, insisti, quando da passagem da Faculdade para o governo do Estado, na divisảo da Bibliotéca em duas secções, entregues a primeiros escriturarios, com a responsabilidade, uma, de todo o serviço técnico e, outra, de todo o expediente. Assim, o chefe se tornaria um sim- 
ples coordenador e orientador. Não seria mais preciso que fosse um técnico, porém apenas um funcionario ativo e dedicado.

\section{CLASSIFICAÇÃOO}

O atual auxiliar técnico está perfeitamente senhor do sistema de classificação adotado. A Bibliotéca tem nêle um funcionario excelente, não havendo necessidade de sugestões para a melhoria dos trabalhos a seu cargo, porquanto as soluções virão dele mesmo à medida que se tornarem necessarias.

\section{EXPEDIENTE}

Todo o serviço de expediente está entregue ao Snr. Agilulpho Candido Dias, funcionario tambem dedicadissimo e ativo. Nada ha tão pouco a observar quanto á boa execução dos serviços a seu cargo. Quanto à distribuição de funções e serviços da Bibliotéca, em relação á atividade que demandam, quer na parte técnica, quer na administrativa, tive a honra de submeter a essa Diretoria, em dezembro ultimo, um memorial em que se resumem as necessidades que me pareceram dignas de registo, e se sugere a reorganização do quadro dos funcionarios. Ainda hoje, essas ponderações se me afiguram procedentes, salvo, evidentemente, melhor juizo.

\section{DESINFECĢÃO E REENGADERNAÇÃO}

E' imprescindivel manter a desinfecção como vem sendo feita. O novo chefe deverá zelar especialmente pela saúde das obras da Bibliotéca, cuja reconstituição paciente vem sendo efetuada metódicamente. Em hipótese alguma se deverá desprezar essa parte obscura do serviço. Seria abandonar novamente à destruição rapida, e, desta vez, definitiva, grande numero de preciosidades. Justificando essas observações do meu antecessor, a Faculdade adquiriu e fez instalar na oficina de encadernação uma estufa termo-quimica, para desinfecção de livros, a qual se acha em experiencias sob o controle e responsabilidade dos fabricantes. Provada satisfatoriamente a eficacia desse aparelho, o serviço de desinfecção dos livros da Bibliotéca poderá ser feito com maior presteza e celeridade do que à mão, como até agora se fazia.

\section{PERMUTAS}

O serviço de permutas compreende duas partes distintas:

1) a permuta de duplicatas com interessados que vêm à $\mathrm{Bi}$. blictéca; 
2) a permuta com bibliotécas e instituições estrangeiras.

E' imprescindivel continua-lo, intensificando-o cada vez mais. Muito se conseguiu nestes dois ultimos anos; porém, ainda ha muito por fazer. E' preciso, porém, que o chefe esteja sempre com os olhos voltados para as possibilidades, que se movimente e faça tentativas, escrevendo, enviando brochuras, inventando expedientes para interessar as instituições estrangeiras que não mostram em geral grande interesse pelas cousas do Brasil. Como exemplo do que afirmo, basta dizer que a permuta com a "Columbia Law Review" nos custou um ano de correspondencia. Idem, com a "Harvard Law Review".

Outras até hoje se recusam. Outras atenderam imediatamente. Para outras instituições somos obrigados a enviar, além da Revista, téses e outras publicações que obtemos em duplicata. Para satisfazer a essas criteriosas ponderações do meu antecessor e atender a determinação da Diretoria da Faculdade, iniciei uma revisão do Catálogo de Duplicatas, já muito antiquado e incompleto, afim de se poder informar, diréta e seguramente, os interessados residentes fóra de São Paulo, das obras que poderão haver permuta.

\section{REVISTA}

Acerca desta parte das atribuições do chefe da Bibliotéca, disse o meu antecessor no citado relatorio:

" $E$ ' indispensavel que a Revista continue a ser publicada trimestralmente. Sei quanto é dificil faze-lo. Ao Chefe Técnico competirá obter as colaborações e isso lhe custará tempo e expediente. Sem a constante preocupação da Revista não lhe será possivel bota-la na rua nas datas certas. E' ainda imprescindivel que não descuide da secção bibliografica. A bibliografia publicada tem dado ótimos resultados e trazido doações importantes. Nem sempre, porém, os professores ajudam. E' preciso que o secretario da Revista faça, às vezes, a critica, submetendo-a apenas aos professores. $\mathrm{Na}$ Revista, as secções de pareceres e trabalhos universitarios é que devem merecer os maiores carinhos. São a parte da atualidade".

Sob minha responsabilidade de secretario da Redação da "Revista da Faculdade de Direito de São Paulo" foram publicados os fasciculos III e IV, que completam o volume XXX, correspondente ao ano de 1934. Saiu aquele em meiados de outubro ultimo e êste em meiados do corrente mês.

S. Paulo, 31 de Dezembro de 1934.

LEONEL VAZ DE BARROS

Chefe Técnico 


\section{ANEXO N. 3 \\ Relatorio dos serviços da Tesouraria e Contadoria em 1934}

\section{CONTADORIA}

$O$ ano de 1934 ofereceu dois periodos distintos: um, que se estendeu de $10^{\circ}$ de janeiro a 10 de abril, em que a Faculdade esteve subordinada exclusivamente ao Governo Federal; outro, que se estendeu de 10 de abril a 31 de dezembro, em que, por força da transferência da Faculdade, operada pelo decr. fed. n. ${ }^{\circ} 24.102$ e consequente incorporação à Universidade de $\mathrm{S}$. Paulo, passou ela a ser regulada pelo regime estadoal. O primeiro periodo corresponde até 31 de março de 1934, ao periodo adicional do exercicio de 1933 , exercicio êste que foi distendido até aquela data pelas disposições do dec. fed. $n .^{\circ} 23.150$, de 15 de setembro de 1933, que estabeleceu as normas para elaboração e execução do orçamento da Receita e Despesa da União. Dessa fórma, incorporadas ao exercicio de 1933, as ocorrencias dêsse periodo fizeram parte do relatorio dêsse ano. A esse relatorio foi anexado o balanço geral e demais demonstrações dos serviços da Contadoria, relativos a êsse exercicio, encerrado em 31 de março de 1934.

De $1 .^{\circ}$ a 10 de abril, não se verificou nenhuma operação, a não ser o vencimento de uma conta a prazo fixo.

Transferida a Faculdade em 10 de abril para o Governo do Estado, iniciava-se uma fase, que vinha sujeitar as operações a cargo da Contadoria, à disposições novas, pertinentes ao regime estadoal. Para efeito de apresentar ao Govêrno do Estado o balanço geral da Faculdade, na data da transferência, preliminarmente, teve a Contadoria de dirigir-se ao Exmo. Snr. Dr. Candido Mota, Diretor em exercicio, solicitando esclarecimentos necessarios ao levantamento desse balanço.

Recebidas as instruções que se faziam precisas, procedeu-se ao inventario geral dos bens existentes e levantou-se o balanço geral 
que, acompanhado do competente relatorio e demonstrações a ele referentes, foi apresentado ao Exmo. Snr. Dr. Waldemar Ferreira, então diretor em exercicio, para ser encaminhado ao Exmo. Snr. Secretario de Estado da Educação e Saúde Publica. Expedido em 9 de maio o dec. est. $n .^{\circ} 6.429$, que aprovava o regulamento da Faculdade e dava outras providências, dispondo que as despesas cabiveis ao Estado seriam pagas pelos cofres da Faculdade e a êstes restituidas posteriormente, teve a Contadoria de atender à organização dos serviços necessarios para dar execução às disposições dêsse decreto, entre os quais cumpre destacar a organização do serviço de pagamento de funcionarios e professores, articulado com a Tesouraria. 0 volume e os caracteristicos proprios dessa tarefa foram objeto de atenção especial e requereram organização tambem especial, visto como a Tesouraria e a Contadoria não tinham a seu cargo serviço de tal natureza. Assim, pois, foi necessario organiza.lo, para tanto tendo sido criadas fichas especiais para acompanhar o pagamento de vencimentos e descontos em folha de cada funcionario, bem como traçados os modelos de formularios que foram precisos. Tivemos necessidade de entrar em constantes entendimentos com o Tesouro do Estado e Secretaria da Educação, para obtenção das tabelas de vencimentos, tabelas de descontos e de mais informes relativos a êsse serviço. E' com grande satisfação que consignamos aqui a boa vontade e grande solicitude com que fomos atendidos pelos dignos funcionarios dessas repartições. Não podemos deixar de consignar o nosso agradecimento particular aos Snrs. Cesario Coimbra, Dr. Sylvio Penteado, Gustavo Arantes, Luiz Machado e Sylvio Fontes, do resouro do Estado e ao Snr. Bressane, da Secretaria da Educação, aos quais repetidamente recorremos e pelos quais fomos sempre distinguidos com atenção particular que nos dispensaram, facilitando a nossa tarefa. Esse serviço de pagadoria, é com satisfação que dizemos, foi levado a cabo com todo o rigor e a organização dada contribuiu com pleno êxito para a boa ordem e exatidão do serviço. Nêsse periodo, ainda a Contadoria forneceu as bases e elementos necessarios para que o Conselho Técnico elaborasse o orçamento da Faculdade para 1935. Ao ser o mesmo encaminhado para aprovação e atendendo à solicitação da Comissão de Orçamento e Regência Patrimonial, enderaçada por intermedio da Reitoria da Universidade, fez a Contadoria uma minuciosa exposição de estudo desse orçamento.

Apresentou tambem uma demonstração circunstânciada das Obras de Refórma, cuja parte que já foi paga atingiu até 3-12-1934, a Rs. 1.051:422\$075. Elaborou tambem esta Secção uma demonstração completa dos pagamentos e descontos relativos ao titulo Folha de 
Vencimentos, efetuados de maio a dezembro. Este trabalho foi encaminhado à Secção de Averbações do Tesouro do Estado, para que esta Seção preparasse em tempo oportuno as fichas individuais e anotasse os descontos efetuados, como se fazia necessario para que, a partir de janeiro, o movimento de Folha de Vencimentos fosse atendido diretamente pelo Tesouro. Foi tambem organizada e remetida ao Rio a tabela das gratificações adicionais que cabiam aos professores da Faculdade, atendendo-se à solicitação da Diretoria de Contabilidade do Ministerio de Educação e Saúde Publica.

Com a aposentadoria do Snr. Antonio José de Freitas, que exercia as funções de Almoxarife, foi esse cargo atribuido ao Snr. Geraldo da Silva Leite. Por ocasião da passagem do Almoxarifado daquele funcionario para êste, fez-se a verificação do "stock", lavrando-se a seguir o termo de entrega. Os demais serviços normais afetos à Contadoria desenvolveram-se em ordem. Foi encerrado o Balanço Geral em 31 de dezembro de 1934.

\section{TESOURARIA}

Os serviços da Tesouraria, intimamente ligados com os da Contadoria, desenvolveram-se com absoluta regularidade.

Alèm dos serviços normais de arrecadação e pagamento de despesas que já fazia, atendeu a Tesouraria, no decorrer do exercicio de 1934, a todo o serviço extraordinario relativo à Folha de Pessoal, a cargo do Gov. Estadoal, que não pouco trabalho aumentou. Em 14-4-35, foi dado balanço nos cofres da Tesouraria, para verificação do saldo em 28-3-35. Esse saldo foi encontrado exato, como faz certo o termo da verificação feita pelos Snrs. Drs. Antonio de Sampaio Doria e Mario Masagão. Esse saldo, na importancia de $35: 623 \$ 290$, foi o que passou para $0.2 .^{\circ}$ periodo do ano de 1934 , óra apreciado. Durante esse $20^{\circ}$ periodo, isto é, de abril a 31-12-34, o movimento global de recebimentos atingiu a 690:875 $\$ 200$, parcela esta que somada ao saldo do exercicio de 1933 (em 28-3-34), perfaz o total de 726:498\$490. Donde, tendo o movimento de pagamentos atingido a $720: 912 \$ 300$, passa para o exercicio de 1935, a importancia de 5:586\$190, como saldo de Caixa.

Todo êsse movimento foi. devidamente escriturado nos livros da Tesouraria e executado obedecendo todo ele às formalidades necessarias.

S. Paulo, 31 de dezembro de 1934.

HEITOR DE SOUSA LIMA

Tesoureiro
CASSIO JOSE' DE TOLEDO Contador 